\title{
COMPUTATIONAL OPTIMIZATION AND IMPLEMENTATION OF CONTROL SYSTEM FOR MECHATRONIC TREADMILL WITH BODY WEIGHT SUPPORT SYSTEM
}

\author{
Grzegorz Gembalczyk, SŁawomir Duda, Eugeniusz Świtoński \\ Silesian University of Technology, Department of Theoretical and Applied Mechanics, Gliwice, Poland \\ e-mail: grzegorz.gembalczyk@polsl.pl; slawomir.duda@polsl.pl; eugeniusz.switonski@polsl.pl
}

\begin{abstract}
The purpose of this paper is to present a novel mechatronic system for gait re-education which consists of a body weight support system (BWS system) and a treadmill. This publication covers mainly issues related to the design and optimization process of a control algorithm dedicated for the unloading system. The proposed control system is based on a fuzzy logic controller coupled with a PID regulator. The optimization of parameters for regulators has been conducted based on numerical simulations in which a hybrid optimization method combining a genetic algorithm with a gradient algorithm has been used. The developed control system has been tested experimentally.
\end{abstract}

Keywords: gait reeducation, control system, optimization, fuzzy logic

\section{Introduction}

Half of all deaths are caused by cardiovascular diseases in the modern world. It is estimated that the number of deaths due to stroke can reach $7.69 \mathrm{mln}$ people to 2030 , and it will constitute one of more important medical problems. Strokes constitute the main reason for permanent disability in the adult population, particularly after turning 60 . They are one of the main reasons for remaining in the condition of disability for a longer period of time. The restoration of possibility to move or keep balance in the upright position is significant for patient's proper functioning. The deficit connected with the lack of ability to walk pertains to almost $70 \%$ of patients who have experienced a stroke. Kinesiotherapy is the most common and obvious way of treatment after a stroke that should be started as soon as possible. The simplest form of exercises is walking in company of a physiotherapist using simple devices for support such as walkers or banisters. Mechatronic devices which support the process of kinesiotherapy after a stroke are in some sense "packed with the latest technological solutions". They affect training efficiency and, especially, improve the speed of walking, endurance and balance. Such devices support physiotherapists relieving them from hard physical work of supporting a patient and allowing them to concentrate on the essence of the exercises carried out to a greater degree (Koceska and Koceski, 2013; Kot and Nawrocka, 2012). These devices both implement the rehabilitation process and verify the progress of treatment. When analyzing rehabilitation devices for kinesiotherapy within a dozen years, it is possible to notice that unloading a patient is the most significant element subject to continuous modifications. It is possible to find in the market devices with a simple design that make it possible to unload a patient in a passive way as well as technologically advanced solutions with active body weight support systems. In the case of passive systems (unloading force regulated by a crank, counterweight, spring, etc.), the difference between the unloading force that is set and the one that is measured during exercises is much bigger (Frey et al., 2006). Therefore, the exercises with devices equipped in body weight support systems with active control of the unloading force are more beneficial for patients. When comparing rehabilitation 
devices equipped with active body weight support systems with one another, it is possible to notice that the unloading mechanism is an element connected with a still supporting structure (it does not keep up with a patient's movement) in most cases; and the patient's walk forces the manipulator (mechanic orthosis) or treadmill movement (Chen et al., 2013; Pajor and Herbin, 2015). In the second case, training is recommended for people who have regained the ability to walk in a degree that makes it possible to move independently, but they still require support and improvement of the technique, speed and stamina (Mehrholz et al., 2014; Cao et al., 2014; Querry et al., 2008). The technologies of biofeedback and virtual reality are also used in the devices of this type (Koenig et al., 2011; Lünenburger et al., 2007, Jurkojć et al., 2017).

A device in which the movement of a training person is limited only by the space of a supporting frame, on which a BWS system moves, has been created as a result of research at the Institute of Theoretical and Applied Mechanics financed by the National Centre for Research and Development (Duda et al., 2016). The possibility of free side movements of a patient's pelvis plays a significant role in rehabilitation exercises that restore the proper pattern of walking, as research shows (Dragunas and Gordon, 2016; Mignardot et al., 2017).

A new form of a mechatronic device for the re-education of walking has been currently developed.

It is a combination of a movable body weight support system with a treadmill. The thing that differentiates the proposed solution from those existing on the market results from coupling the movement of an exercising person with the movement of a treadmill tape. It is not the treadmill movement that forces patient's movement. It is the patient that forces treadmill movement. It is implemented by using a sensor measuring the inclination angle of a sling rope. Moreover, the device allows free side movements that are so important for proper rehabilitation. It is achieved thanks to drive in a direction that is transverse to the direction of walking. The invented mechatronic system for gait re-education includes four drives:

- two independently working drives of the body weight support system,

- the drive of a winch trolley making it possible for training a person to move in the direction that is perpendicular to the plane of the patient's movement,

- the drive of the treadmill tape.

This publication involves an attempt at developing and optimizing a control system of the body weight support system with a fuzzy logic controller. No such solutions have been found in literature. Systems used for unloading a patient with an automatically regulated force are usually described in a very general way. Most of all, there are no descriptions of systems steering winches equipped with two drives cooperating with each other. The minimization of mass and size constitutes an important construction condition in the case of unloading systems with mobile BWS systems that have been suspended to the ceiling in the current solutions (Hidler et al., 2011; Duda et al., 2016). However, it is connected with the limitation of a linear drive movement range. The right synchronization of the work of a winding drum with a linear actuator is necessary if one wants to make it possible for patients to do exercises with significant movements. Due to limited movement of such a linear actuator, the development of an optimal steering system constitutes an interesting engineering problem. This is why the problem of optimization of a system controlling the BWS system has been tackled in this article.

The most detailed description of a similar system was presented by Frey et al. (2006) describing the Lokolift device. A winding drum cooperates with a rope (passive) drive in that solution. In order to steer this winding drum, switches have been used which are activated at the moment when the movement of the linear actuator (instantaneous or mean) goes beyond the admissible range. Thus, the engine that propels the rope drum works only with the nominal speed or it does not work at all.

The Lokolift system is meant mainly for the cooperation with a patient training on the treadmill, and its whole construction is placed on the floor. Therefore, this device does not have 
to meet restrictive criteria connected with the minimization of mass and dimensions, so the range of the linear actuator is not limited by any restrictive conditions. Taking into account the way devices for the re-education of walking develop and the beneficial influence of mobile body weight support systems on the stability of a patient's walk when training in reduced weight conditions, it is possible to expect further development of similar devices (Reinkensmeyer and Dietz, 2016; Riener et al., 2010).

\section{Description of the device}

The device used for the re-education of walking presented in this paper is a mechatronic system in which the body weight support system, the system of compensating side inclinations and the training treadmill have been integrated (Fig. 1).

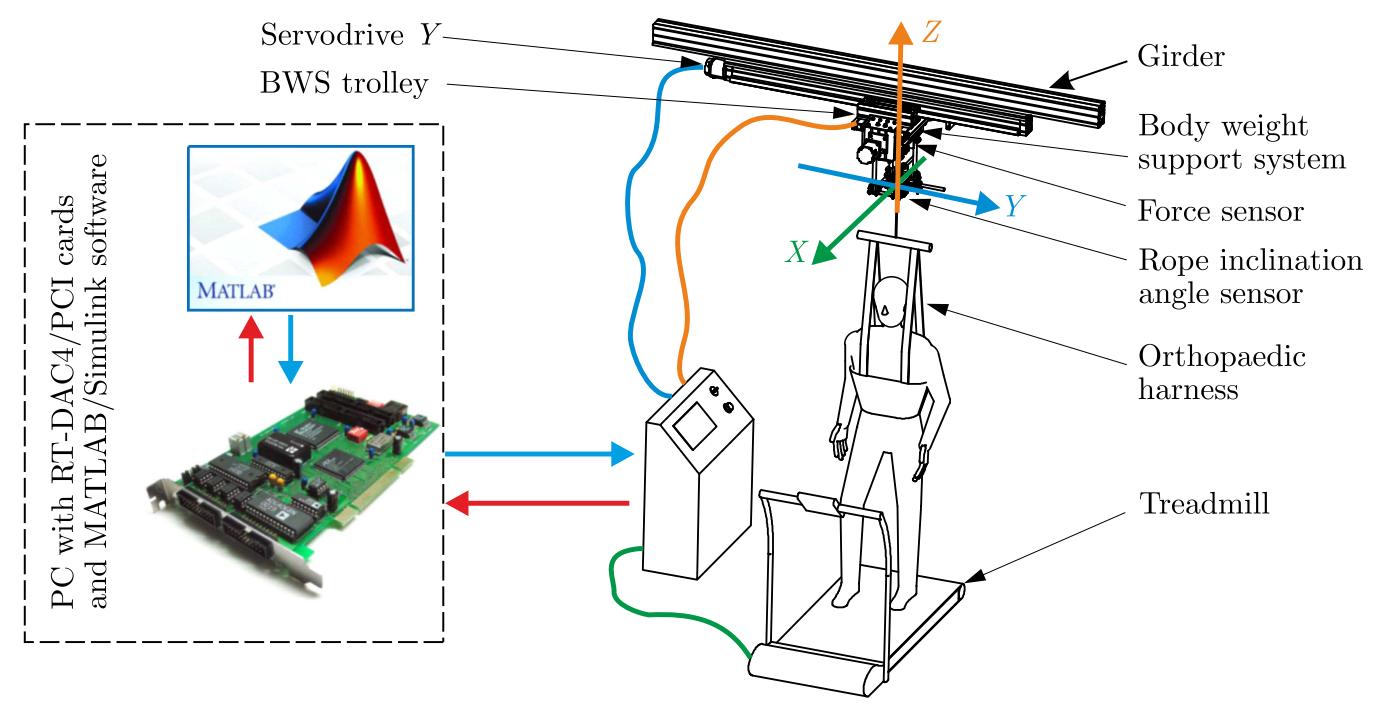

Fig. 1. Mechatronic device for gait re-education

A training person is pinned up in a special orthopaedic harness fastened to the rope of a winching device. The coupling between the mentioned subsystems and the patient is implemented through measurement systems, one measuring the unloading force and the other measuring linear movements resulting from the deflection of the line from the vertical axis (sensors) and particular mechanism drives (actuators). The encoders of servo drives are additional servers that the device is equipped with.

The transmission of measurement and control signals of the device takes place in the real time mode (Miądlicki and Pajor, 2015; Sapiński et al., 2016) with the use of a computer equipped with 2 RT-DAC4/PCI cards and MATLAB/Simulink software. The calculation step of the real time is $T_{0}=0.01 \mathrm{~s}$. The servo drives of the winching device and compensation of side inclinations work in the speed control mode. Then, the generated steering signals retain the set rotational speed in a precise way.

Steering the treadmill, described in details in (Duda et al., 2017), takes place by a modified original control panel. It has been achieved by parallel connection of an additional controller whose task involves simulation of the work of buttons placed on the panel that steers the treadmill. The electronic system has been built with the use of optocouplers steered with digital signals generated by the steering system in a PC Computer. The change of a signal from a high status to a low one and back to the high status has been obtained after $0.1 \mathrm{~s}$. It is equivalent to the change of the treadmill speed obtained after pressing the button (faster or slowly) on 
the control panel of the treadmill. This is also the reason for a relatively low sensitivity of the steering system to changes of walking parameters.

A tracking system with a PD controller has been implemented for controlling the movement of the BWS system trolley (servodrive $Y$ ) along a girder. Descriptions of such a system were presented in (Duda et al., 2016; Raczka et al., 2013). Controlling a BWS system requires the use of a more advanced active control system which is presented in Section 5.

\section{Modelling the body weight support system}

The processes of optimization of complex steering algorithms in which several or dozen parameters should be specified are usually carried out with offline methods. These methods are basically necessary in the case of tuning steering systems with devices meant for cooperation with people; for rehabilitation in particular. In order to carry out the optimization of a system controlling a BWS system it is necessary to develop a numerical model taking into account the coupling between the electric part, the mechanical one, and the patient. A model of a synchronous motor with permanent PMSM magnets (Permanent Magnet Synchronous Motor) described in (Mężyk et al., 2016; Xu, 2012) has been used for building the numerical model of the device.

The body weight support system that is responsible for unloading the patient with the set force is the most important subsystem of the device presented in the article. In contrast to classic hoist devices, its driving system has been equipped with two independently working engines. The first one that is marked as $Z 1$ is responsible for propelling the rope drum; the second one ( $Z 2$ linear actuator) is connected with the system of dynamic compensation. This system works on the drive basis of a Series Elastic Actuator type (SEA) (Pratt and Williamson, 1995; Robinson et al., 1999). Figure 2 presents a detailed construction of the driving system. The

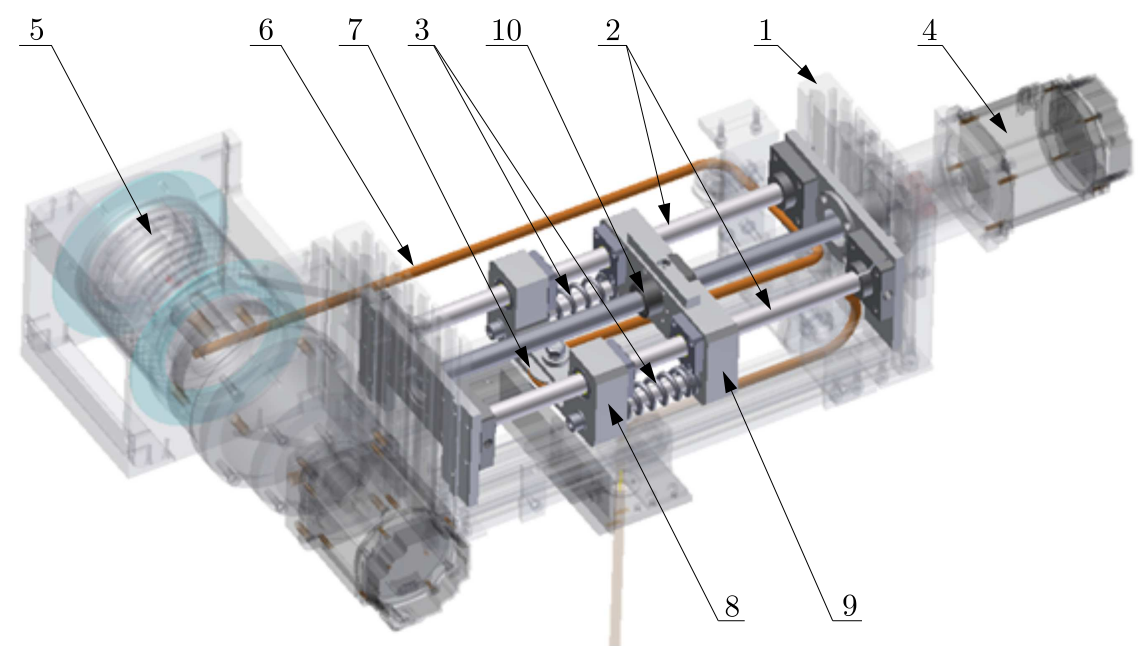

Fig. 2. The structure of the driving system of the body weight support system

construction of the BWS system has been developed on the basis of aluminium profiles creating supporting frame (1) to which the following have been fixed: track guides (2), compression springs (3), driving engine of the $Z 2$ axis, winding drum with an engine (5), and a system of pulleys. The construction of the presented system makes it possible to change rope length (6) through a change of the location of the pulley (7). This pulley is fixed to the first steel trolley out of two (8) that move along tracking guides (2) and are separated with springs (3). This diminishes the consequences of impact loads appearing during operation. The movement of the second trolley (9) is implemented with a linear drive with ball screw (10) of a $5 \mathrm{~mm}$ pitch whose rotation causes movement of a nut that is fastened to this trolley (9). The maximum range of the $Z 2$ linear actuator movement is ca. $110 \mathrm{~mm}$. 
The developed physical model of the BWS system is shown in Fig. 3a, after including simplifying assumptions.

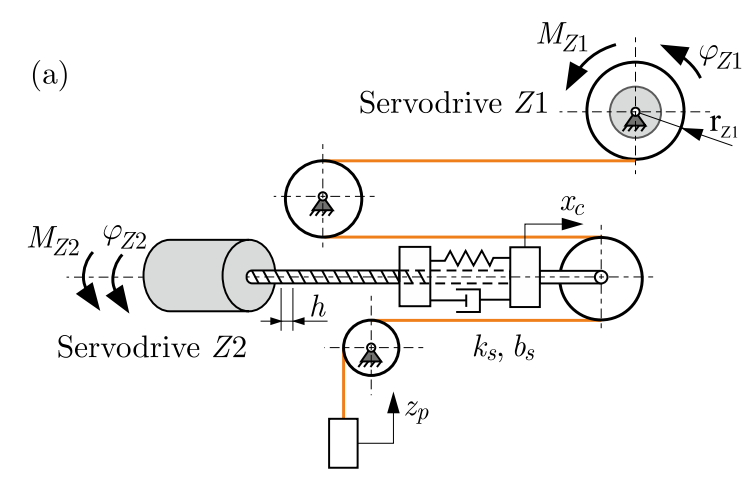

(b)

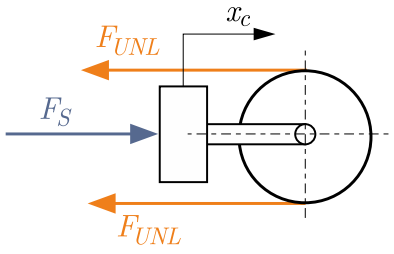

Fig. 3. (a) The physical model of the BWS system. (b) The forces which act on the actuator $Z 2$

Three generalized coordinates connected with the rotation angles of rotators in the engines and the shift of the patient's centre of gravity have been accepted in the mathematical model of the presented system

$$
\mathbf{q}=\left[\varphi_{Z 1}, \varphi_{Z 2}, z_{p}\right]
$$

If one takes into account the fact that the resistance to movement and the trolley weight whose movement is marked with the $x_{c}$ coordinate are negligibly small, then one can estimate the value of the unloading force influencing the patient (rope tension force) $F_{U N L}$, when considering the forces influencing this trolley (Fig. 3b)

$$
F_{U N L} \approx \frac{F_{s}}{2} \quad F_{s}=k_{s}\left(\varphi_{Z 2} \frac{h}{2 \pi}-x_{c}\right)+b_{s}\left(\dot{\varphi}_{Z 2} \frac{h}{2}-\dot{x}_{c}\right)
$$

where

$$
x_{c}=\frac{z_{p}-\varphi_{Z 1} i_{Z 1} r_{Z 1}}{2}
$$

In the equation above, $i_{Z 1}$ specifies the planetary gear ratio between the rope drum and the $Z 1$ engine. In the mathematical model of the BWS system, the mass of the propelling screw and the trolley propelled by it have been reduced to the moment of inertia of the $Z 2$ engine shaft. The inertia of other pulleys, the winding drum, and the planetary gear has been reduced to the moment of inertia of the $Z 1$ engine shaft. In such a case, the searched equations of motion have the following form

$$
\begin{aligned}
& \ddot{\varphi}_{Z 1}=\frac{1}{I_{Z 1}}\left(M_{Z 1}-b_{Z 1} \dot{\varphi}_{Z 1}-F_{U N L} i_{Z 1} r_{Z 1}\right) \\
& \ddot{\varphi}_{Z 2}=\frac{1}{I_{Z 2}}\left(M_{Z 2}-b_{Z 2} \dot{\varphi}_{Z 2}-2 F_{U N L} \frac{h}{2 \pi}\right) \\
& \ddot{z}_{p}=\frac{1}{m_{p}}\left(F_{U N L}-m_{p} g\right)
\end{aligned}
$$

The coupling between the electric and mechanical part is implemented in such a way that the driving moment determined from the numerical model of the PMSM motor $\left(M_{Z 1}\right.$ and $\left.M_{Z 2}\right)$ has been implemented in the model of the mechanical part (3.4). The calculated angular acceleration $\left(\ddot{\varphi}_{Z 1}\right.$ and $\left.\ddot{\varphi}_{Z 2}\right)$ has been, in turn, used in the engine model for calculating the rotation speed and the rotor rotation angle. 


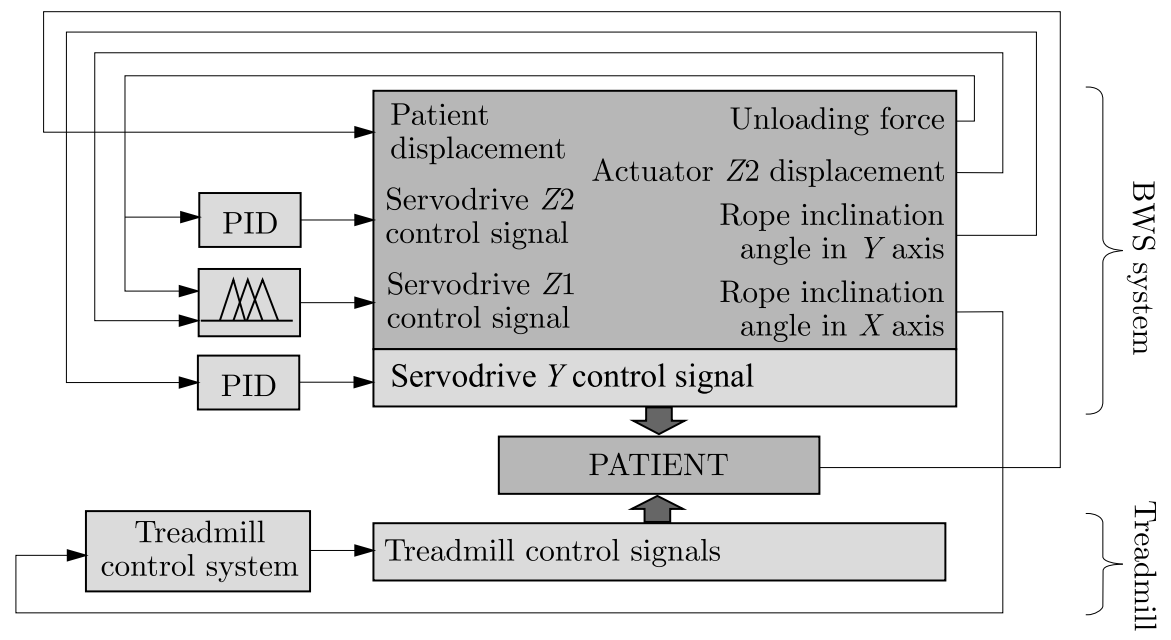

Fig. 4. A functional scheme of a mechatronic treadmill for locomotive training

Figure 4 shows a functional plan of the device in a block form in which the servo drives, the mechanical part (BWS system and treadmill), patient's movement, and the steering system have been included.

Parameters of the mathematical model have been determined on the basis of catalog data, experimental tests on the universal testing machine and in the estimation process. The estimation of parameters in the models of $Z 1$ and $Z 2$ servo drives has been carried out on the basis of catalogue data and experimental data in which the rotational speed of the engine in various strain conditions has been registered. The validation of the model developed for the BWS system (Fig. 3a) has been carried out with the use of a weight of $20 \mathrm{~kg}$ hung at the end of the rope. During the experiment, the rotational speed of 1000 (rotations/per minute) has been set on the $Z 1$ engine; and the value of the unloading force has been measured at the same time. Analogical tests have been carried out with the use of the $Z 2$ drive. The correlation coefficient has been calculated with R-Pearson's method (Gniłka and Mężyk, 2015), and it equals 0.87.

\section{Modelling the patient's gait}

A kinematic input has been used in further numerical research for simulation of the patient's movements. Thus, the third equation has been reduced in the system of equations of the BWS system movement, see Eq. (3.4).

The equations describing patient's movements $z_{p}[\mathrm{~m}]$ (used to calculate the force $F$ in accordance with equations (3.2) and (3.3)) have been described with mathematical functions whose formulas have been formulated on the basis of parameter measurements of walking of the disabled person. The results of the research of walk kinematics with participation of people after a stroke with paresis of the right side have been used in the model. The analysis of the walk kinematics has been carried out with the use of APAS software. Taking into account the fact that the BWS system should also guarantee a reliable work during doing other exercises in which vertical movements have a wide range (e.g. squats, climbing stairs), this input has been described by the system of equations

$$
z_{p}= \begin{cases}0 & \text { for } t<2 \\ 0.016[\sin (2 \pi(t-2))-\sin (4 \pi(t-2))] & \text { for } 2 \leqslant t<5.166 \\ 0.2(t-5.166) & \text { for } 5.166 \leqslant t<6.166 \\ 0.2 & \text { for } t \geqslant 6.166\end{cases}
$$




\section{Optimization of the control system}

The results of a preliminary experimental study of the control systems of the presented body weight support system has shown that the use of the $Z 2$ drive only is sufficient for ordinary walking on a treadmill (Duda and Gembalczyk, 2016). In the case when a rehabilitated person is supposed to do a different exercise which involves a significant change of the trunk (e.g. squats, standing up from a chair, climbing obstacles), it is necessary to start a winding drum- the $Z 1$ drive.

In order to take advantage of the device potential fully and to guarantee a patient the biggest comfort of exercises done possible, one should develop and tune steering systems designated separately for every performed exercise or several main modes of the device operation.

From the point of view of physiotherapists, a simple system with few options is desired. Therefore, a universal steering system that will be able to steer a device independently of the patient's behaviour is an optimal solution for them. An attempt at developing a universal steering system of the BWS system has been made to meet these expectations taking into account economic aspects at the same time (energy efficiency). On the basis of earlier experience, the proposed steering system has been based on a PID controller coordinating with a fuzzy controller (Zhao et al., 2007). The $Z 2$ drive is steered in a feedback loop with the sensor of the unloading force, whereas the $Z 1$ drive controller additionally uses movement measurement of the $Z 2$ drive actuator. This solution is presented in the form of a scheme in Fig. 5.

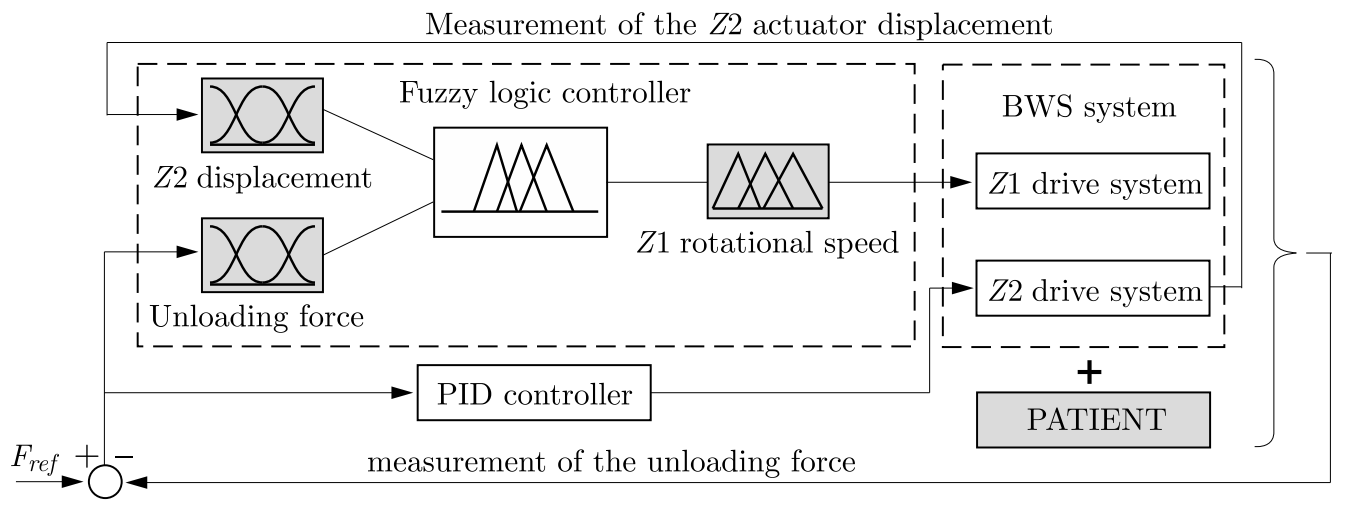

Fig. 5. Block diagram of the proposed control system

The basis of rules of the fuzzy controller has been prepared in such as way so that the $Z 1$ drive is started only in the situation when the $Z 2$ actuator moves away from the admissible working range or when the deviation of the reliving force is bigger than the accepted admissible deviation. The accepted set of rules is presented in the table. Seven membership functions have been defined for every input and output signal of the fuzzy controller. The symbol of $Z 2$ disp means movement of the actuator in the $Z 2$ drive, whereas $\Delta U N L$ is the value of the unloading force error

$$
\Delta U N L(t)=F_{r e f}-F_{U N L}(t)
$$

The signs from "- - " to " +++ " represent the value from the lowest to the highest one. The "nom" index means that the variable value is placed within the accepted admissible range, where the operation of $Z 1$ is not required. The assumed admissible range for moving the $Z 2$ actuator is $10 \mathrm{~mm}\left(Z 2 D_{\text {nom }}= \pm 10 \mathrm{~mm}\right)$, and the admissible deviation of the unloading force $20 \mathrm{~N}$ $\left(\Delta U N L_{n o m}= \pm 20 \mathrm{~N}\right)$. Moreover, the following ranges of the input signals have been accepted

$$
\Delta U N L \in\langle-100 ; 100\rangle[\mathrm{N}] \quad Z 2_{\text {disp }} \in\langle-50 ; 50\rangle[\mathrm{mm}]
$$


Table 1. The basis of fuzzy logic controller rules

\begin{tabular}{|c|c|c|c|c|c|c|c|c|}
\hline & \multicolumn{7}{|c|}{ Displacement of the $Z 2$ actuator $\left(Z 2_{\text {disp }}\right)$} \\
\hline & & --- & -- & - & nom & + & ++ & +++ \\
\hline \multirow{7}{*}{ 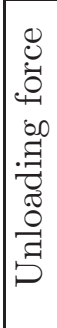 } & $\Delta U N L---$ & 0 & 0 & $Z 1+$ & $Z 1++$ & $Z 1+++$ & $Z 1+++$ & $Z 1+++$ \\
\hline & $\Delta U N L--$ & 0 & 0 & 0 & $Z 1+$ & $Z 1++$ & $Z 1+++$ & $Z 1+++$ \\
\hline & $\Delta U N L-$ & 0 & 0 & 0 & 0 & $Z 1+$ & $Z 1++$ & $Z 1+++$ \\
\hline & $\Delta U N L$ nom & $Z 1--$ & $Z 1--$ & $Z 1-$ & 0 & $Z+$ & $Z 1++$ & $Z 1++$ \\
\hline & $\Delta U N L+$ & $Z 1---$ & $Z 1--$ & $Z 1-$ & 0 & 0 & 0 & 0 \\
\hline & $\Delta U N L++$ & $Z 1---$ & $Z 1---$ & $Z 1--$ & $Z 1-$ & 0 & 0 & 0 \\
\hline & $\Delta U N L+++$ & $Z 1---$ & $Z 1---$ & $Z 1---$ & $Z 1--$ & $\overline{Z 1-}$ & 0 & 0 \\
\hline
\end{tabular}

The optimal values of the PID controller settings and the range of the accepted membership functions of input signals in the fuzzy controller have been searched for in the process of optimization. Both controllers have been optimized separately due to the accepted assumptions. The input has been limited only to simulation of walking itself during the selection of the PID controller settings. The simulation time has been limited to $t<5.166$ in Eq. (4.1). The settings of the PID controller have been the optimized variables, whereas the goal function has been connected with the minimization of the unloading force error

$$
F C_{P I D}=\int_{0}^{5.166}|\Delta U N L(t)| d t \rightarrow \min
$$

The optimization of the fuzzy controller has been started with the acceptance of the relevant convention of generating membership functions. The coordinates of four additional points $P_{1}-P_{4}$ are calculated for each input in the proposed approach. The relevant membership functions are created in the next step on their basis. The values of these points are calculated with the use of the factors of proportionality included in the vector of the decision variables $x(n)$, and their detailed description is included in equations (5.4). The decision variables describe the proportion of the section division between the final value of the range and the previous section point. They can assume values in the range from 0 to 1 . The maximum values of $P_{\max }$ and the admissible $P_{\text {nom }}$ result from the accepted assumptions

$$
\begin{array}{ll}
P_{1}=x(1)\left(P_{\max }-P_{\text {nom }}\right) & P_{2}=x(2)\left(P_{\max }-P_{\text {nom }}\right) \\
P_{3}=x(3)\left(P_{\text {max }}-P_{2}\right) & P_{4}=x(4)\left(P_{\max }-P_{3}\right)
\end{array}
$$

Two types of the membership functions have been used in the fuzzy controller, the triangular and trapezoid ones. The visualisation of the developed convention is pictured in Fig. 6 .

The presented solution has been used for description of the membership functions for both inputs so values of 8 variables have been looked for in the process of optimization.

The ranges of the membership functions of the output signal (values of the set rotational speed of the $Z 1$ engine) have been accepted as constants in accordance with Fig. 7 .

Both the unloading force and movement of the $Z 1$ drive should be taken into account during fuzzy controller optimization in the goal function. Due to the limit switches that are used in the device, the most important criterion connected with the position of the $Z 2$ actuator is that none of the trolleys goes beyond the working range. This criterion is included in the form of a penalty function. Moreover, it is important to ensure fluent regulation of the unloading force in order to ensure the biggest patient's comfort. It is achieved by limiting the second derivative of this value in terms of time. The minimization of such a component also affects the energy efficiency 


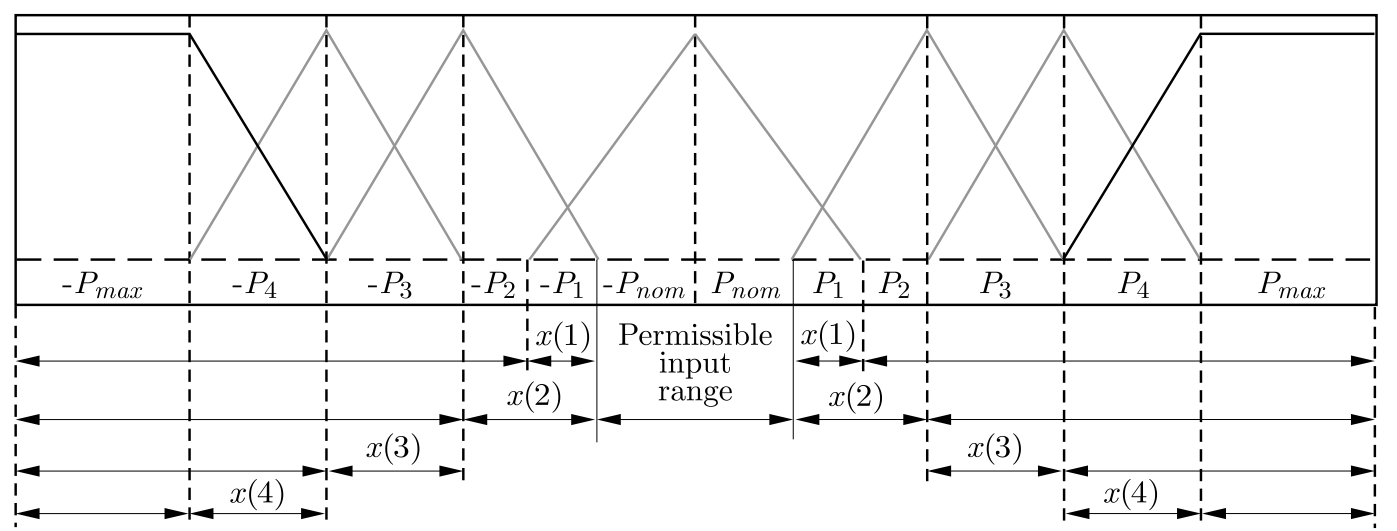

Fig. 6. Visualization of the developed method of describing the input membership functions

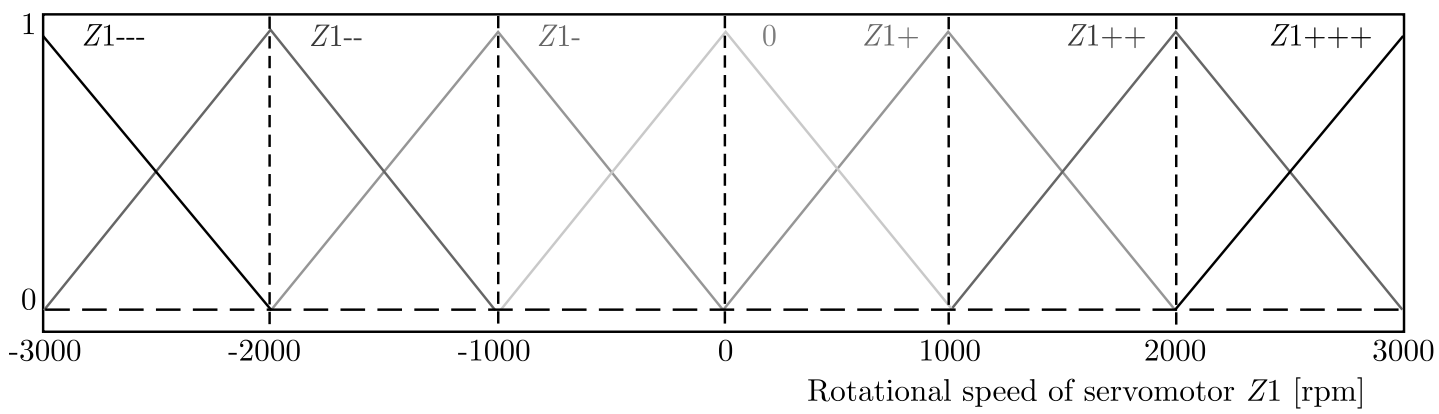

Fig. 7. Output membership function for rotational speed of the servomotor $Z 1$

of the device. The inclusion of all the aspects discussed above has allowed for formulating a multi-objective goal function with the internal penalty function

$$
\begin{aligned}
& F C_{f u z z y}=\left(1-w_{1}-w_{2}\right) \int_{0}^{T}|\Delta U N L(t)| d t+w_{1} \int_{0}^{T} \frac{d^{2}|\Delta U N L(t)|}{d t^{2}} d t \\
& +w_{2} \int_{0}^{T}\left|\omega_{Z 1}(t)\right| d t+\int_{0}^{T}|\Delta U N L(t)| P(t) d t \rightarrow \min
\end{aligned}
$$

where

$$
P(t)= \begin{cases}0 & \text { if } \quad Z 2_{\text {disp }}<40 \mathrm{~mm} \\ 10^{4} & \text { if } \quad Z 2_{\text {disp }}>40 \mathrm{~mm}\end{cases}
$$

The optimization of both controllers has been carried out with the use of the Optimization Toolbox module that is implemented in the MATLAB software making use of a hybrid optimization method combining a genetic algorithm with a gradient algorithm for continuous optimization with limitations (fmincon function). The best individual created in the genetic algorithm constitutes the starting point for calculations with the gradient method in the calculations carried out. The research carried out has shown that it is most advantageous to use the PD controller for steering the $Z 2$ drive with the following settings:

$$
P=57,13 \quad I=0 \quad D=0.755
$$

The case in which the weight factor $w_{1}=0.005, w_{2}=0.02$ has been considered the best one after analysis of the set of paretooptimal solutions obtained during the optimization of the fuzzy controller. The obtained distribution of the membership functions and a graphic interpretation of the output signal (as a surface) are shown in the three consecutive figures. 


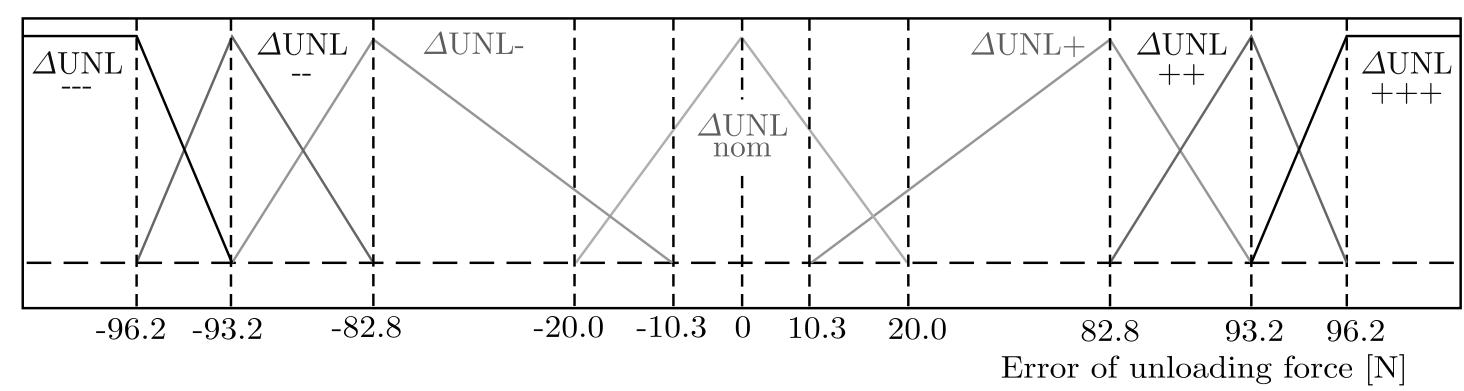

Fig. 8. Input membership function for unloading the force error

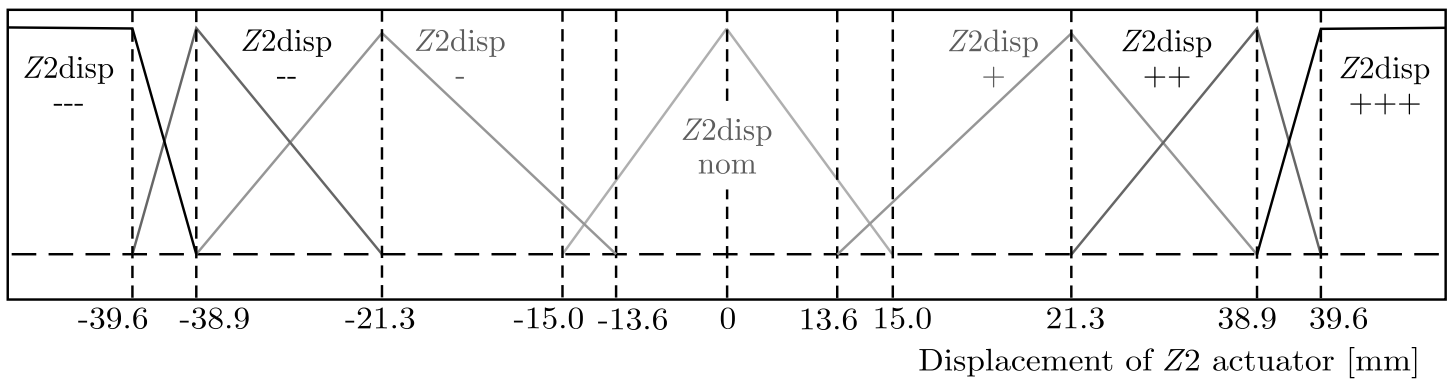

Fig. 9. Input membership function for displacement of the $Z 2$ actuator

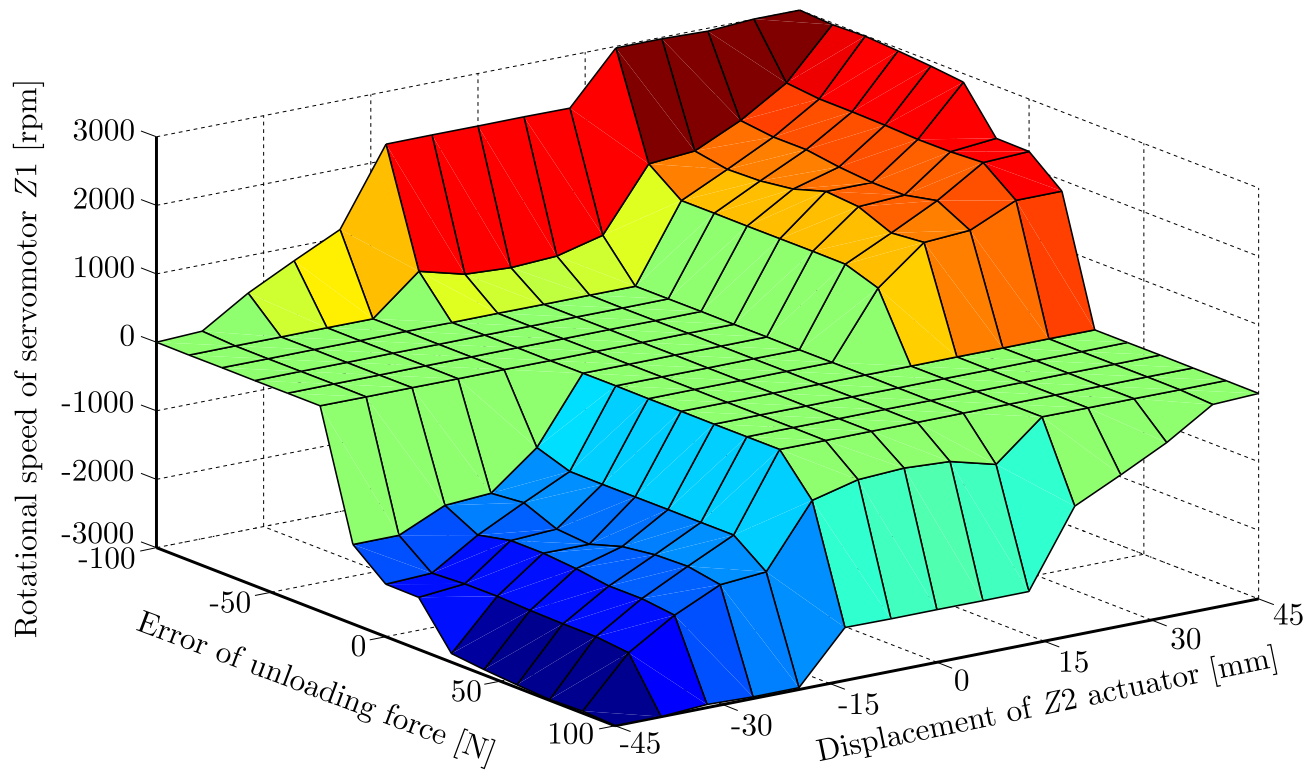

Fig. 10. Surface of the fuzzy logic controller output signal

\section{Results of experimental research}

In order to verify the developed algorithm controlling the drives of the unloading system, a series of experiments has been conducted. In the presented results, the operation of the BWS drive systems has been tested during walking on a treadmill with a constant speed $2 \mathrm{~km} / \mathrm{h}$, but the set value of the unloading force has been changed and equaled to 50,120,180, 300 and $180 \mathrm{~N}$, respectively.

The charts show the registered value of the unloading force (Fig. 11), rotational speed of the servomotor $Z 2$ (Fig. 12), displacement of the actuator in the $Z 2$ drive system (Fig. 13) and the rotational speed of the servomotor $Z 1$ (Fig. 14). 


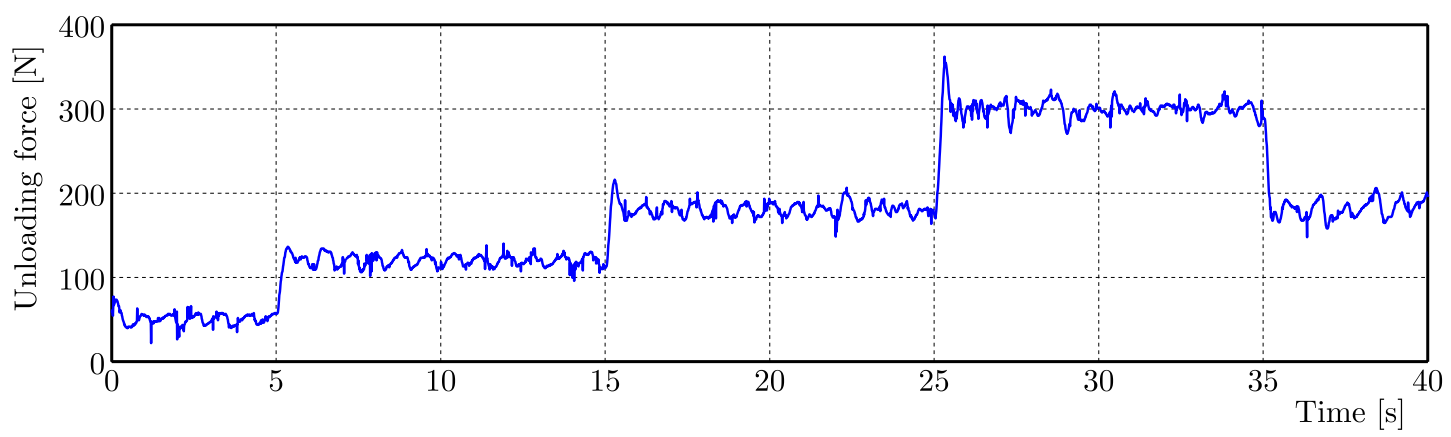

Fig. 11. Registered value of the unloading force as a function of time

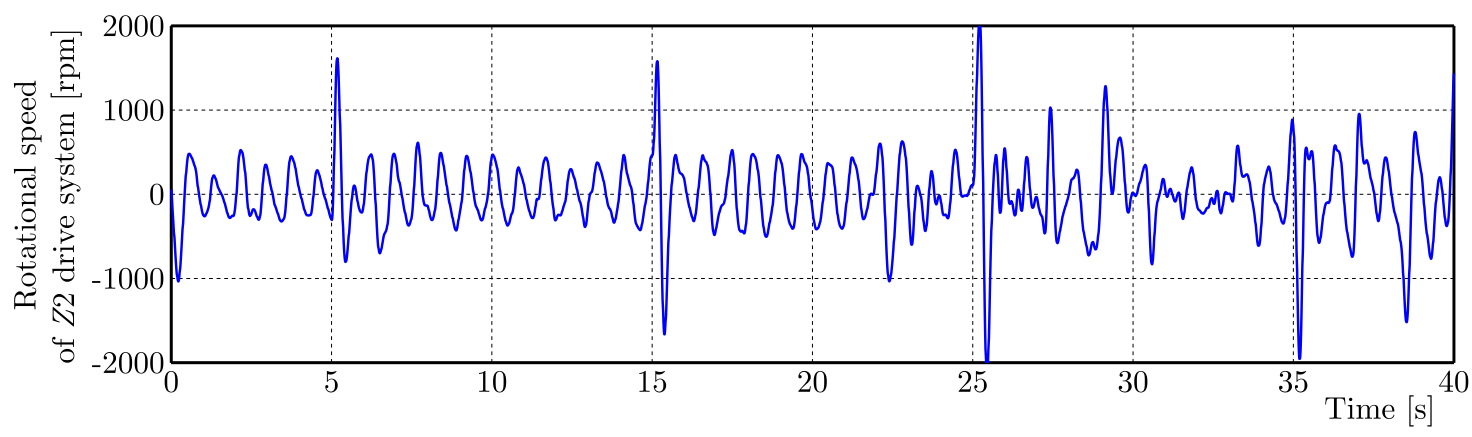

Fig. 12. Registered value of the $Z 2$ servomotor rotational speed as a function of time

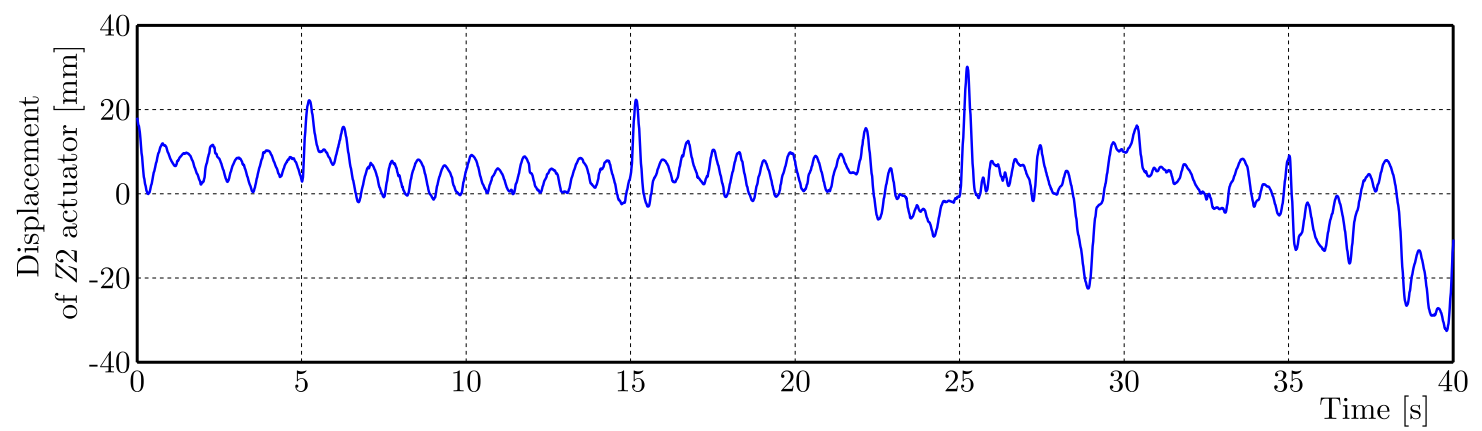

Fig. 13. Registered linear displacement of the $Z 2$ actuator as a function of time

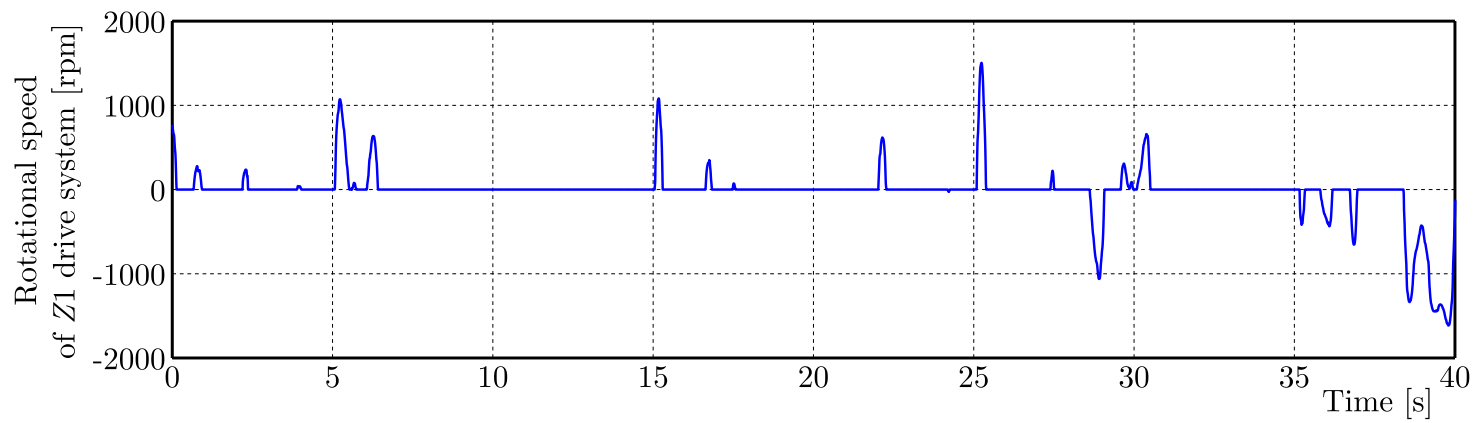

Fig. 14. Registered value of the $Z 1$ servomotor rotational speed as a function of time

\section{Conclusions}

The paper presents a mechatronic device supporting the process of walking re-education in which the body weight support system cooperates with the training treadmill, and has the possibility of making follow-up movements with side movements of the patient.

The use of a fuzzy controller makes it possible to develop a universal steering system that ensures the maintenance of a constant unloading force value and synchronizes the operation of 
the winding drum with the SEA drive type independently of the exercise done. The proposed solution is particularly beneficial for physiotherapists supervising a patient because it requires introduction of the unloading force value only. It is a particularly important advantage as the simplicity of handling is expected.

As the charts show, the drive of the $Z 1$ winding drum is started only in the situation when the $Z 2$ actuator is close to the limit switches; it is not, however, used during normal walking on the treadmill. It is an advantage in economic terms. Testing the device by a healthy person only is a certain limitation of the conducted research; however, it is a beneficial situation for the verification of the steering system operation as the exercising person can move in a more dynamic way.

\section{References}

1. CaO J., Xie S.Q., Das R., Zhu G.L., 2014, Control strategies for effective robot assisted gait rehabilitation: the state of art and future prospects, Medical Engineering and Physics, 36, 12, 1555-1566

2. Chen G., Chan C.K., Guo Z., Yu H., 2013, A review of lower extremity assistive robotic exoskeletons in rehabilitation therapy, Critical Reviews in Biomedical Engineering, 41, 4-5, 343-363

3. Dragunas A.C., Gordon K.E., 2016, Body weight support impacts lateral stability during treadmill walking, Journal of Biomechanics, 49, 13, 2662-2668

4. Duda S., Gąsiorek D., Gembalczyk G., Kciuk S., Mężyk A., 2016, Mechatronic device for locomotor training, Acta Mechanica et Automatica, 10, 4, 310-315

5. Duda S., Gemalczyk G., 2016, Experimental study on the fuzzy-PID hybrid control algorithm for unloading system in mechatronic device for gait re-education, Proceedings of VII European Congress on Computational Methods in Applied Sciences and Engineering, 6567-6573

6. Duda S., Gembalczyk G., Switonski E., 2017, Design study and development of mechatronic treadmill for gait reeducation, Engineering Dynamics and Life Sciences. Proceedings of 14 th International Conference Dynamical Systems Theory and Applications 2017, 183-191

7. Frey M., Colombo G., Vaglio M., Bucher R., Jörg M., Riener R., 2006, A novel mechatronic body weight support system, Neural Systems and Rehabilitation Engineering, 14, 3, 311-321

8. GNiŁkA J., MĘŻYK A., 2017, Experimental identification and selection of dynamic properties of a high-speed tracked vehicle suspension system, Eksploatacja i Niezawodność - Maintenance and Reliability, 19, 1, 108-113

9. Hidler J., Brennan D., Black I., Nichols D., Brady K., 2011, ZeroG: Overground gait and balance training system, Journal of Rehabilitation Research and Development, 48, 4, 287-298

10. Jurkojć J., Wodarski P., Bieniek A., Gzik M., Michnik R., 2017, Influence of changing frequency and various sceneries on stabilometric parameters and on the effect of adaptation in an immersive 3D virtual environment, Acta of Bioengineering and Biomechanics, 19, 3, 129-137

11. Koceska N., Koceski S., 2013, Review: robot devices for gait rehabilitation, International Journal of Computer Applications, 62, 13, 1-8

12. Koenig A., Omlin X., Bergmann J., Zimmerli L., Bolliger M., Müller F., 2011, Controlling patient participation during robot assisted gait training, Journal of Neuroengineering and Rehabilitation, 8, 14-25

13. Kот A., NAwrockA A., 2012, Balance platform system dynamic properties, Journal of Vibroengineering, 14, 1, 178-182

14. Lünenburger L., Colombo G., Riener R., 2007, Biofeedback for robotic gait rehabilitation, Journal of Neuroengineering and Rehabilitation, 4, 1 
15. Mehrholz J., Pohl M., Elsner B., 2014, Treadmill training and body weight support for walking after stroke, [In:] Cochrane Database of Systematic Reviews, 1, John Wiley \& Sons, Ltd

16. Mężyk A., Klein W., Fice M., Pawlak M., Basiura K., 2016, Mechatronic model of continuous miner cutting drum driveline, Mechatronics, 37, 12-20

17. Miądlicki K., Pajor M., 2015, Real-time gesture control of a CNC machine tool with the use Microsoft Kinect sensor, International Journal of Scientific and Engineering Research, 6, 538-543

18. Mignardot J.B., Le Goff C.G., van Den Brand R., 2017, A multidirectional gravity-assist algorithm that enhances locomotor control in patients with stroke or spinal cord injury, Science Translational Medicine, $\mathbf{9}$

19. Pajor M., Herbin P., 2015, Exoskeleton of upper limb - model using real movement parameters (in Polish), Modelowanie Inżynierskie, 26, 57, 40-46

20. Pratt G.A., Williamson M.M., 1995, Series elastic actuators, IEEE International Conference on Intelligent Robots and Systems, 399-406

21. Querry R.G., Pacheco F., Annaswamy T., Goetz L., Winchester P.K., Tansey K.E., 2008, Synchronous stimulation and monitoring of soleus H reflex during robotic body weightsupported ambulation in subjects with spinal cord injury, Journal of Rehabilitation Research and Development, 45, 1, 175-186

22. Raczka W., Sibielak M., Kowal J., Konieczny J., 2013, Application of an SMA spring for vibration screen control, Journal of Low Frequency Noise, Vibration and Active Control, 32, 1-2, $117-131$

23. Reinkensmeyer D.J., Dietz V., 2016, Neurorehabilitation Technology, Springer, International Publishing

24. Riener R., Lünenburger L., Maier I.C., Colombo G., Dietz V., 2010, Locomotor training in subjects with sensori-motor deficits: an overview of the robotic gait orthosis lokomat, Journal of Healthcare Engineering, 1, 2, 197-216

25. Robinson D.W., Pratt J.E., Paluska D.J., Pratt G.A., 1999, Series elastic actuator development for a biomimetic walking robot, Proceedings of IEEE/ASME International Conference on Advanced Intelligent Mechatronics, 561-568.

26. Sapiński B., RosóŁ M., WęGrzynowski M., 2016, Investigation of an energy harvesting MR damper in a vibration control system, Smart Materials and Structures, 25, 12, 125017, 1-15

27. Snamina J., Kowal J., Orkisz P., 2013, Active suspension based on low dynamic stiffness, Acta Physica Polonica A, 123, 6, 1118-1122

28. Xu W.J., 2012, Permanent magnet synchronous motor with linear quadratic speed controller, Energy Procedia, 14, 364-369

29. Zhaо C.S., Zhu S.J., He Q.W., 2007, Fuzzy-PID control method for two-stage vibration isolation system, Journal of Theoretical and Applied Mechanics, 45, 1, 171-177 